\title{
Estimation of Iranian price elasticities of residential electricity demand
}

\author{
Yeganeh Mousavi Jahromi ${ }^{\mathrm{a}}$, Mostafa Heidari Haratemeh ${ }^{\mathrm{b}}$, Morteza Mahmodi Meymand ${ }^{\mathrm{c}}$ and Mohsen \\ Ameri Shahrabi ${ }^{\mathrm{d}^{*}}$
}

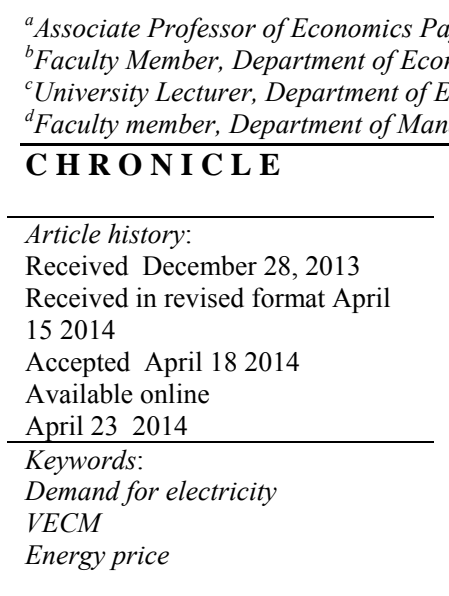

\section{Introduction}

For years, there were major concerns on how to control energy consumption and increase productivity of energy production. There have been tremendous efforts to find some replacement for traditional energy resources such as solar energy, wind farms, etc. Taylor (1975) is believed to be first who presented a survey and critique of the econometric literature on the demand for electricity, which was focused on residential, commercial and industrial demand. Lin and Ouyang (2014) tried to specify the determinants of sectoral electricity demand, predict future electricity consumption by building a model using the Johansen cointegration methodology and estimated the sectoral electricity conservation potential. Their results indicated that growth domestic product per capita was the leading force explaining the sectoral electricity consumption increase, while value-added per worker, research and development intensity and electricity price were the primary factors contributing to the sectoral electricity consumption decrease. The results also demonstrated that sectoral electricity consumption in 2020 would be $369.79-464.83$ billion $\mathrm{kWh}$ under the low-growth scenario and ${ }^{*}$ Corresponding author.

E-mail addresses: mohsenamerishah@yahoo.com (M. Ameri Shahrabi) 
530.14-666.39 billion kWh under the high-growth scenario in China. Bartusch and Alvehag (2014) performed a comprehensive study on exploring the potential of residential demand response programs in electricity distribution. Yan and Folly (2014) performed an investigation of the impact of demand elasticity on electricity market using extended Cournot approach. Wood and Alsayegh (2014) investigated the effect of oil prices, economic diversification policies and energy conservation programs on the electricity and water demands in Kuwait. Fell et al. (2014) presented a new look at residential electricity demand using household expenditure data. They applied publicly available expenditure data and utility-level consumption data from several major U.S. cities, complementing studies that implemented individual billing data. Mahmoudi et al. (2014) presented a new demand response (DR) scheme from the retailers' point of view.

Arisoy and Ozturk (2014) estimated the price and income elasticity of industrial and residential electricity demand in Turkey over the period 1960-2008. They used Kalman filter to estimate time varying parameters model and reported that the income and price elasticities of industrial and residential electricity demand were lower than unity. The income elasticity of demand had a positive sign and it was statistically significant which was 0.979 and 0.955 for industrial and residential electricity demand, respectively. Thus, an increase in per capita electricity consumption was less than increase in per capita income. In addition, the estimates of price elasticity seemed to be inelastic for both residential and industrial electricity demand. Therefore, the price increase will not discourage residential and industrial electricity demand and consumers will indicate little response to electricity price variations because electricity was a necessary good.

Okajima and Okajima (2013) estimated elasticities of Japanese residential price electricity over the period 1990-2007 by using the first difference generalized method of moment estimator to prevent dynamic panel bias. The results indicated that while short-run elasticities were similar to those in previous studies, long-run elasticities were significantly lower in our study. They also determined that the price elasticity of Japanese residential electricity consumption was notably influenced by income inequality and severe weather. Based on these results, they provided some insights to tailor environmental taxation to effectively attain the Kyoto Protocol. Mostafavi et al. (2013) presented a novel machine learning method for estimation of electricity demand in Thailand.

\section{The proposed study}

This paper presents a study to determine demand for electricity in city of Yazd, Iran over the period of 1998-2008. The study uses vector error correction model (VECM) based on seasonal information as follows,

$$
\Delta X_{t}=\mu+\sum_{i=1}^{p-1} \Gamma_{i} \Delta X_{t-i}+\alpha\left(\beta \quad X_{t-1}+\text { atrend }\right)+A Z_{t}+\varepsilon_{t}
$$

where $X_{t}$ is an $\mathrm{n} \times 1$ vector, which represents long term relationship, $Z_{t}$ is an $\mathrm{m} \times 1$ vector, which represents short term relationship, $\mu$ is the vector of intercept and $\beta(\mathrm{n} \times 1)$ is a long term matrix, $a$ represents long term coefficients and finally $\varepsilon_{t}$ represents residuals, which are assumed to be normally distributed. In this relationship $X$ and $Z$ are defined as follows,

$X=\left(C O, P_{C}, P_{G T}, P_{G M}, Y\right)^{t}$,

$Z=(T, M)^{t}$,

where $C O$ represents consumption of electricity per kilowatt, $P c$ states the price of electricity of each kilowatt, $P_{G T}$ is the price of each cubic meter natural gas, $P_{G M}$ is the price of each cubic meter liquid gas, $Y$ denotes national income per capita, $\mathrm{M}$ is the number of household consumer of electricity and 
finally $T$ represents temperature of the city. The first step in Johansen cointegration algorithm is to examine co-integration rank of each variable and our investigation shows that $C O, T, P G T, Y$ and $M$ are $\mathrm{I}(1)$ and $\mathrm{P}_{\mathrm{c}}$ and $\mathrm{P}_{\mathrm{GM}}$ are $\mathrm{I}(2)$.

\section{The results}

In this section, we present details of our findings on the implementation of Johansen and Juselius algorithm (1990).

$$
\begin{gathered}
D(C o)=-0.14[\operatorname{Co}(-1)+1.09 P c(-1)-1.27 I(-1)-2 P G M(-1)-0.97 P G T(-1)+71.99] \\
\quad+0.25 D C o(-4)+0.63 D P c(-4)+0.51 D I(-4)+2.1 D P G M(-4) \\
-1.49 D P G T(-4)+0.14 T+0.94 M \quad R^{2}=90 \quad \bar{R}^{2}=87 \quad F=30.8 \\
C o=71.99-1.09 P C+1.27 Y+2 P G M+0.97 P G T
\end{gathered}
$$

t-student (3.21) (3.51) (-2.52) $\quad(-3.49) \quad(-3.94)$

As we can observe from the results of Eq. (5), all statistical observation are meaningful when the level of significance is five percent. The sign of all coefficients are meaningful, which means there is an increase on electricity consumption as the amount of national income per capita or the price of each cubic meter gas increases. In addition, as the price of electricity increases, we see a reduction on price of electricity on long-term horizon. Table 1 shows the short-term effects of changes on prices on demand on electricity.

\section{Table 1}

The summary of short term effect

\begin{tabular}{cccc}
\hline Variable & coefficient & Standard coefficient & t- student \\
\hline$\Delta \mathrm{CO}$ & 0.25 & 0.19 & 1.29 \\
$\Delta \mathrm{PC}$ & -0.63 & 0.32 & 1.96 \\
$\Delta \mathrm{I}$ & 0.51 & 0.8 & 0.63 \\
$\Delta \mathrm{PGM}$ & 0.5 & 1.14 & 1.8 \\
$\Delta \mathrm{PGT}$ & -1.49 & 1.37 & -1.09 \\
$\mathrm{M}$ & 0.94 & 0.81 & 1.15 \\
$\mathrm{~T}$ & 0.14 & 0.09 & 1.49 \\
\hline
\end{tabular}

In order to study the effects of short-term and long-term of price of electricity on demand of electricity in city of Yazd we summarize the results of our survey in Table 2 as follows,

\section{Table 2}

The effects of short-term and long term of price of electricity on demand for electricity

\begin{tabular}{ccccc}
\hline \multicolumn{2}{c}{ Price elasticity } & & \multicolumn{2}{c}{ Income elasticity } \\
\cline { 1 - 3 } Short-term & Long-term & & Short-term & Long-term \\
\hline 0.63 & -1.09 & & 0.51 & 1.27 \\
\hline
\end{tabular}

The results of Table 2, we can understand that in short-term, an increase of one unit on income only increases demand of electricity for about 0.51 . However, an increase of one unit on income will increase demand by 1.27 over the long time. In addition, an increase on price of electricity may reduce demand for electricity over the long-term period.

\section{Conclusion}

During the past few years, there have been increasing concerns on energy consumption in Iranian economy. It is believed that government of Iran pays the highest expenses on subsidizing energy in the world. The government has tried to make some payment to all Iranian families and increase 
energy prices such that people are encouraged to consume less. The results of our survey have shown that any increase on energy prices could reduce demand only over the long term period and it will not have any short term effect. The results of our survey are consistent with findings of Arisoy and Ozturk (2014), Okajima and Okajima (2013) and Zhou and Teng (2013). However, the results were somewhat inconsistent with findings of Okajima and Okajima (2013).

\section{Acknowledgement}

The authors would like to thank the anonymous referees for their comments on earlier version of this paper.

\section{References}

Arisoy, I., \& Ozturk, I. (2014). Estimating industrial and residential electricity demand in Turkey: A time varying parameter approach. Energy, 66(1), 959-964.

Bartusch, C., \& Alvehag, K. (2014). Further exploring the potential of residential demand response programs in electricity distribution. Applied Energy, 125, 39-59.

Fell, H., Li, S., \& Paul, A. (2014). A new look at residential electricity demand using household expenditure data. International Journal of Industrial Organization, 33, 37-47

Johansen, S., \& Juselius, K. (1990). Maximum likelihood estimation and inference on cointegration -with applications to the demand for money. Oxford Bulletin of Economics and statistics, 52(2), 169-210.

Lin, B., \& Ouyang, X. (2014). Electricity demand and conservation potential in the Chinese nonmetallic mineral products industry. Energy Policy, 68, 243-253.

Mahmoudi, N., Saha, T. K., \& Eghbal, M. (2014). A new demand response scheme for electricity retailers. Electric Power Systems Research, 108, 144-152.

Mostafavi, E. S., Mostafavi, S. I., Jaafari, A., \& Hosseinpour, F. (2013). A novel machine learning approach for estimation of electricity demand: An empirical evidence from Thailand. Energy Conversion and Management, 74, 548-555.

Okajima, S., \& Okajima, H. (2013). Estimation of Japanese price elasticities of residential electricity demand, 1990-2007. Energy Economics, 40, 433-440.

Taylor, L. D. (1975). The demand for electricity: a survey. The Bell Journal of Economics, 6(1), 74110.

Wood, M., \& Alsayegh, O. A. (2014). Impact of oil prices, economic diversification policies and energy conservation programs on the electricity and water demands in Kuwait. Energy Policy, 66, 144-156.

Yan, J., \& Folly, K. (2014). Investigation of the impact of demand elasticity on electricity market using extended Cournot approach. International Journal of Electrical Power \& Energy Systems, 60, 347-356.

Zhou, S., \& Teng, F. (2013). Estimation of urban residential electricity demand in China using household survey data. Energy Policy, 61, 394-402. 